[Sullivan, K. (2002). Unreal Tournament: The Battle Over the New Zealand Social Studies Curriculum. New Zealand Annual Review of Education, 11, 179-197]

\section{Unreal Tournament: The Battle Over the New Zealand Social Studies Curriculum}

\section{KEITH SULLIVAN}

\section{Abstract:}

This article examines the process and content of the highly contentious social studies curriculum recently introduced in New Zealand. Essentially, there was a conflict between two ideological perspectives: that of the social democrats who wrote the original draft, and that of the neo-liberals as represented by the Education Forum. The article concludes that in the contest over the new curriculum, the social democrat perspective nominally gained the upper hand.

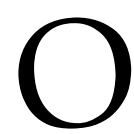

13 November 2001, in her morning programme on National Radio, Kim Hill featured an article about Unreal Tournament, a simulated combat game. This game has an editing facility that allows the cutting and pasting of local sights and personalities into the game. With these new features in place, you can launch cyber space rocket attacks on the Beehive and assassinate Members of Parliament. Ms Hill suggested that one of her guests, Jonathan Hunt, Speaker of the House, could be the target of such an attack. Other guests were Bill Hastings, New Zealand's Chief Censor, and Scott McKay, a partner in a Petone game parlour where Unreal Tournament is available.

In the recent past, games like Unreal Tournament would have been considered as being perhaps in bad taste but essentially harmless. The September 11th attacks on the World Trade Centre in New York and the Pentagon in Washington, however, have introduced a new perspective. Could such games now be considered repugnant, or even sinister and dangerous? Another response could be that this perspective is an irrational over-reaction and that it is the right of individuals to decide for themselves. On the one hand, there is a call for "law and order"; on the other, for freedom of the individual to make choices and act rationally. In her role as effective interviewer and devil's advocate, Kim Hill drew out the following three perspectives from this situation:

i. The games parlour manager argued that these types of games are "out there", and available to anyone. Although he has not purchased these games, he wondered why he shouldn't capitalise on this opportunity. The implication was that such a game would attract a lot of attention, draw in the customers and be profitable. Besides, if he didn't do it, someone else would!

ii. The Chief Censor stated that although he may not be in favour of such games, there really was not much he could do to stop the use of them. He did state, however, that there is an age restriction upon the game's use and that game parlours, such as the one in Petone, need to uphold the law.

ii Jonathan Hunt was concerned about what he called "copy cat" crimes - that such provocative and violent-content games could encourage people to target individuals in real life and go beyond the fantasy of the games parlour.

\section{Untangling Issues and Forming Opinions - The Stuff of Social Studies}

Underlying these statements are differing and sometimes conflicting points of view based upon different sets of values and beliefs about what people should and should not be able to do. Listening to the arguments, I found myself weighing things up and making judgments about both the issues and the people involved. For instance, what if the games parlour manager decided to adapt his version of the game so that it does depict New Zealand public buildings, such as the Beehive, and so that it does features public figures, such as Jonathan Hunt or even the Prime Minister? In doing this, would he be exercising his rights as a free citizen and also being astute in taking advantage of an excellent opportunity to increase his profits and market share (after all, it's only a game) and contributing to the New Zealand economy in the process (albeit in a small way)? On the other hand, as a citizen, is he being selfish, irresponsible and immoral in pursuing personal gain with little sense of social responsibility (what if a deluded player does go and commit a terrorist act against a public building or attacks a public figure after having played Unreal Tournament!)?

On the other hand, if the Chief Censor can only make public comment and cannot act to make such potentially destructive games 
unavailable, should his powers as censor be increased in order better to protect society? Or, alternatively, is it the case that, in our free and democratic society, such an act would be a curtailment of individual rights?

What about Jonathan Hunt's position? Should he ask his colleagues to raise the issue in Parliament? Does the ongoing climate of deregulation and non-interference in business mean that commonsense and even national security have been swept aside so that market forces can prevail? Or is it healthy stress-release for fantasy game afficionados freely to assassinate public figures and blow up important buildings within the confines of a harmless game rather than doing the real thing?

I selected the above radio feature as an illustration for two reasons. I happened to hear Kim Hill's show just by chance when I was thinking about how best to write about the new and contentious social studies curriculum. There are any number of similar events in any particular day or week on which I have to use my critical skills to disentangle what is occurring and on which I could have similarly focused. Deconstructing this particular event seemed to make sense because I had stumbled upon it so randomly. The article represented the type of reasonably complex day-to-day issues in which, as a participant in New Zealand society, I take part (albeit passively in my own head on this occasion). It is the combination of a whole range of such events over a long period of time that determines how I judge social and political events as they arise, and that in a combined fashion I use to form my understanding of how the world works, and consequently how I should respond. When we participate in such debates (as a passive third party, in this case, or more fully in our daily interactions with others), we listen, tease out the underlying issues, assess the various perspectives, form an opinion, come to a conclusion, and - if appropriate - we respond and act in some way. It is part of being a (responsible) citizen to keep up with issues, to be a contributor (within a small social group or in a larger setting), and to understand what is going on and grasp how things operate, both in their own right but also in relation to the current politics, morality and expectations of society. Such is also the stuff of social studies.

When we go to school, we learn much through what we are taught (both facts and the ability to think - the job of the curriculum); through who teaches us (and how they do this - pedagogy); through those we mix with (other students - the process of socialisation); and through the growing perception of how things relate to the world we live in (our family, community and the wider society - becoming citizens). During the course of our education, one of the most important things we learn to do is to sift through, arrange and critically evaluate the information we are provided with. We learn to do this through all curriculum areas, but understanding how things work so that we can fully participate in society is a specific purpose of social studies. The curriculum statement, Social Studies in the New Zealand Curriculum (1997), describes the intention of the new curriculum as follows:

Social studies education aims to enable students to participate in a

changing society as informed, confident and responsible citizens.

(Ministry of Education, 1997, p. 8)

The question needs to be asked: Does this pragmatic, governmentpolicy description sit comfortably with contemporary expectations of what social studies should be about? A review of the literature suggests that, at least on the face of it, it does. For example, Barr (1997) describes social studies as having two oppositional but complementary roles, socialisation and counter-socialisation. By this he means that, on the one hand, it teaches both explicitly and by implication the democratic values and societal truths which are the foundations of our society. As such it encourages us to be conservative. On the other hand, social studies is also meant to help students develop and encourage critical thinking and to challenge these same conservative foundations; to be open to new ideas; and to experience and acknowledge the different ways of life, belief systems and values - in other words, to also develop radical potentialities. Although this may seem contradictory, life is complex, and learning to deal with contradiction and complexity in a rational and fair fashion is seen as an essential component of education in humane societies, and one of the main purposes of social studies curricula (Parker \& Jarolimek, 1984; Engle \& Ochoa, 1988). ${ }^{1}$

\section{Creating a Social Studies Curriculum for New Zealand}

\section{Some Historical Background}

Meanwhile, another "unreal tournament" has been taking place in the political arena. This has taken the form of a contest of ideologies where a neo-liberal and commerce-driven agenda has replaced, through strategic, hidden and often dishonest means, a more humane social democracy. When the Fourth Labour Government was elected to a second term in 1987, the Treasury produced a two-volume report (The 
Treasury, 1987), the entire second volume of which was devoted to a critique of education. A process of reform aimed at the administration and governance of schools was initiated, and a series of documents was produced: Administering for Excellence (Department of Education, 1988a) (better known as the Picot Report), Tomorrow's Schools (Ministry of Education, 1988b), Today's Schools (Ministry of Education, 1990) and Investing in People Our Greatest Asset (Smith, 1991). The neo-liberal approach of the reforms challenged the essentially social democratic ideological status quo, and a new agenda was developed and put in place (Lauder, 1990; Sullivan, 1997, 1999). A major concern of the neo-liberal reforms was that education was out of line with the needs of the economy. It was also seen as wasteful. The concepts of accountability, efficiency, effectiveness, choice and competition were central. A major neo-liberal argument was that if schools were made to compete in a quasi-marketplace in order to attract students, they would need to improve their quality of teaching and learning. In this situation, principals became managers to whom teachers as employees were accountable through the use of performance contracts and the continuous measurement of pupil progress.

In an uncanny fashion, the impetus created by these reforms of the late 1980s continued through to the mid-1990s, despite several changes of government (from Labour to National to a National/New Zealand First coalition). Instead of being challenged, the neo-liberal policies moved inexorably forward, and seemed to be above party political considerations. What took social democrats by surprise was firstly that educational change had normally been concerned with "the heart of the matter", curriculum and pedagogy, rather than administration. Administration, after all, was only the structure for carrying out the main job, and as such was a servant of education (rather than its master). How to respond to these new issues was unclear. Secondly, the New Right used the "old left's" arguments to criticise the status quo (in effect, both were critical of what was on offer, although their solutions were entirely different). Thirdly, in arguing in economic terms, the neo-liberals claimed the high ground for economic over social issues and in so doing had the support of the government.

For the next stage of this "grand plan", once the intended administrative changes were firmly in place, the focus was to move on to the practice of education, curriculum and assessment.

However, by the time the various curricula were being developed, the social democrats' perspective (maintained by many teachers in the school sector and their counterparts in the early childhood and tertiary sectors), had become more sharply focused. With support from their various unions, educationalists had reorganised, and were responding to the neo-liberal agenda with their own more humanistic vision for education in New Zealand. As they re-grouped, it was reasonably predictable that in this next stage of reform, there would be challenges to the neo-liberal assumptions. More recently, the current Labour Government has come up with the concept of a Third Way, which is envisaged as a middle route combining the best from social democracy and neo-liberalism

Developing a useful social studies curriculum for New Zealand was long overdue. Schools had been working largely with outdated materials. The primary sector was using a syllabus that had been created in 1961 (with the Faces documents added in the 1980s). In secondary schools, forms 1 to 4 were using a syllabus from 1977 (supplemented by a 1991 Ministry of Education social studies handbook). Although the subjects of geography and history were taught, no integrated social studies syllabus existed in the senior secondary school (forms 5 to 7). The creation of a new social studies curriculum would address these perceived deficiencies and also provide an integrated, relevant and comprehensive coverage of the social sciences for the entire 13 years of school, from J1 to form 7.

There was dissension about what the seven essential learning areas should contain, and differing processes were gone through in developing the various curriculum statements. The social studies curriculum was the most controversial and most contested area. The sequence of events could be described as having five stages:

i. 1993 - The release of the New Zealand Curriculum Framework

ii. 1994 - Social Studies in the New Zealand Curriculum: Draft

iii. 1995 - The Education Forum's Social Studies in the New Zealand Curriculum: A Submission on the Draft

iv. 1996 - Social Studies in the New Zealand Curriculum: Revised Draft

v. 1997 - Social Studies in the New Zealand Curriculum - Final

\section{i. 1993: The Release of the New Zealand Curriculum Framework}

In 1993, the New Zealand Curriculum Framework was released, providing the foundation upon which the seven new curricula were to be built. These curricula were to be based on what were designated as the essential learning areas. They aimed to "describe in broad terms the 
knowledge and understanding which all students need to acquire" (p. 8). The seven essential learning areas are: language and languages, mathematics, science, technology, social sciences, the arts, and health and physical well-being.

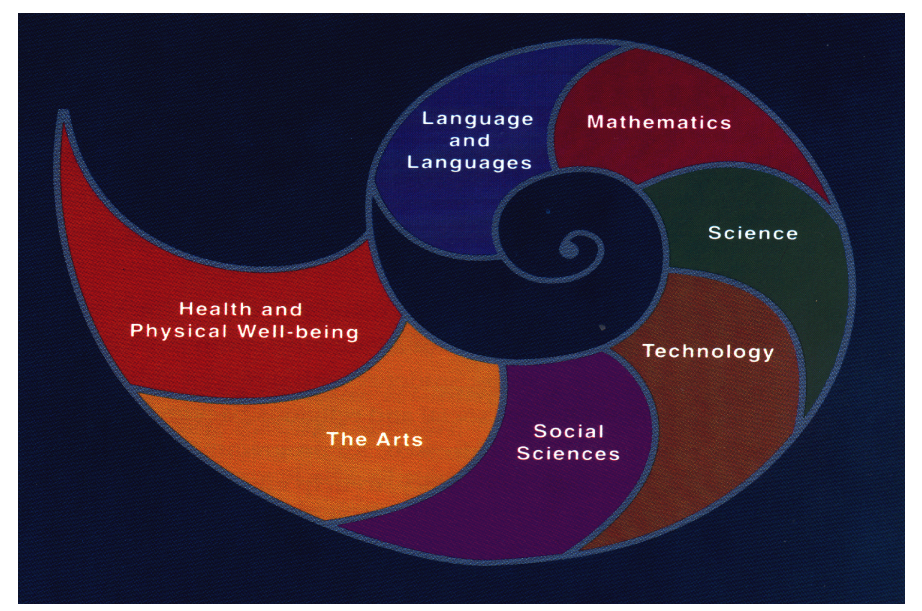

All curriculum statements were to be based on a set of specified principles and would call on and develop eight essential skills (communication, numeracy, information, problem-solving, self-management and competitive, social and cooperative, physical, and work and study skills). Besides providing subject-knowledge, curricula would also clarify and develop attitudes and values, and provide the basis for effective assessment at the school level and for national qualifications. In terms of assessment, achievement aims for the learning areas would be organised as eight levels of achievement which would be spread over the 13 years of schooling. All curricula would build on the experiences of the past, consider the education reviews of the 1980s, and take into account the recent economic and social changes (read "administrative reforms") in New Zealand. The Framework was a clearly articulated document providing specific instructions for how curricula were to be constructed in all of the seven essential learning areas.

It could be argued, however, that the creation of these particular seven essential learning areas arose because of an ideological position. It could be asked why, for instance, an area such as the social sciences was encapsulated in only one essential learning area. After all, it comprises a number of important, separate and well-established disciplines that study human social activity: anthropology, geography (often considered a science), history (often considered a humanity) and sociology. What is more, why was economics (a subject more central to business than social issues) included? Economics had become so central to government policy (and often to the detriment of social policy) that there is a sense that perhaps it was placed in social studies to ensure a sort of "economics capture" which, going on recent performance, would introduce a conservative materialism into a social and liberal area of learning, like a spy into an alien country.

In a similar vein, why was technology, which had never existed as a curriculum subject in its own right, given single learning area status? In our globalising world, information technology, in particular, is seen as leading us into the future, but is it appropriate to reify it by putting technology on an equal footing with the multidisciplinary social sciences? It could also be argued that the lumping together of a wide range of arts subjects is similarly under-valuing. A major issue is that if seven essential learning areas are created, does it mean that their development and implementation are funded in an equal fashion and, if so, would the arts and social sciences end up under-funded and under-valued?

\section{ii. 1994 - Social Studies in the New Zealand Curriculum: Draft}

The Social Studies in the New Zealand Curriculum: Draft (referred to as the Draft from now on) was produced in 1994. The document contained concepts of how social studies should be conceived and taught that radically challenged the recently introduced neo-liberal perspective. In her Foreword, the Secretary of Education at the time, Maris O'Rourke, argued that the Draft was the result of canvassing the social studies teaching community, running the gauntlet of the various levels of bureaucracy of the Ministry of Education, and collaboration between social studies staff from two colleges of education and a team of writers. The Draft was assertively described as the new and definitive social studies curriculum and it was suggested that, although fine-tuning may be needed, essentially this was going to be it.

While the team had taken note of the themes and structures of the New Zealand Curriculum Framework (Ministry of Education, 1993), they had moved beyond them in their interpretation. Five learning strands around which to organise thematic material were created: social organisation and processes; culture and heritage; place and environment; time, continuity and change; and resources and economic 
activities. These replaced the more traditional focus on geography and history. The Framework concept of essential skills was accepted in theory, but astutely adapted and re-cast as social studies skills (Ministry of Education, 1994, p. 26). The social studies skills retained just two of the essential and acceptable ones of the Framework (communication, and social and cooperative skills). Notable omissions were self-management and competitive skills, and work and study skills, which were left out in favour of creative thinking, values exploration, critical thinking, and research and inquiry skills.

There is a sense in which the Framework's essential skills consist of a combination of materialistic/pragmatic and critical/creative skills, and more than a suggestion that the Draft had purposely dropped the former. Neo-liberal criticism of the existing education system (The Treasury, 1987) talked about lack of accountability, efficiency and effectiveness and the inability of the education system to provide an education in tune with the country's economic needs. From a curriculum perspective, it is the self-management and competitive skills, and work and study skills that seem to have been designed to address these concerns. It is the sense of egalitarianism and social responsibility central to the opposing ideological stance of the social democrats that is represented by the social studies skills, particularly values exploration, critical thinking, and social and cooperative skills.

The Draft introduced four cross-strand perspectives "which were to be given emphasis in the suggested contexts and learning areas, across all strands at each achievement level" (Ministry of Education, 1993,

p. 11). These are:

1. The unique nature of Aotearoa New Zealand society

2. New Zealand's relationship with the Pacific

3. New Zealand's relationships with Asia

4. New Zealand's place in the global community.

There are several implications that can be derived from these cross-strand perspectives. Biculturalism and Maori issues are given precedence over other issues. European influences are mentioned but are not predominant, and although British influences are implied, they are not specifically mentioned. The Pacific and Asia are given high priority, and globalisation is conceived as an important issue but largely in terms of its meaning for New Zealand. The main focus is on a post-colonial Aotearoa with a turangawaewae (place to stand) in the Asia Pacific region.
Another important statement is made about "aspects of learning" (Ministry of Education, 1994, pp. 15-18). The document states that as in other areas of learning, students gain "knowledge and ideas", "skills" and "values", and that a fourth aspect of learning that is "specifically relevant to social studies, is social action"

The statements which are made in relation to these four aspects of learning, particularly in regard to values and social action, are central to the philosophical foundation of the Draft. Social studies is intended to teach about what values are, how they vary from situation to situation, and how to make decisions about them:

Social studies encourages students to respect the right of others to hold different values, while exploring and clarifying their own values.

By its approach and content, social studies aims to commit students to respect human dignity, to show concern for others, to respect difference, and to uphold social justice. Commonly held values, such as the welfare of others, collective responsibility, acceptance of cultural diversity, and respect for the environment will be fostered, along with commonly valued attributes such as individual initiative, effort, and responsibility. (p. 17)

Following logically on from this is the turning of values into action Students should be aware that they can influence contemporary and future events. Being involved in developing and applying ideas about people, their actions, and their activities may encourage students to participate in the affairs of the community. They should be given opportunities to contribute constructively, in learning activities which facilitate social action.

Social action at all times must be consistent with the aims of social studies. (pp. 17-18)

Upon examining the Draft in depth, one gains a sense that the development of the social studies curriculum process has been enthusiastically taken up as an opportunity to respond with something innovative and refreshing. In so doing, it has developed several identifiable themes that can be summarised as follows:

- Theme 1: A sense of revisionism - It replaces a passé British and colonial New Zealand with a postcolonial Aotearoa whose lifeblood flows from the Pacific and that needs to build its ties with Asia. The focus here is on a bicultural history emphasising the importance and 
rights of Maori as tangata whenua and of New Zealand's place as a Pacific nation. It implies that history and geography should be seen through the eyes of Maori rather than ethnocentrically through European eyes. It posits that the Treaty of Waitangi is "recognised as the founding document between Maori as tangata whenua and Pakeha in Aotearoa New Zealand".

- Theme 2: Adopting an holistic and postmodern approach - Social studies has been recreated as an inter-connected and responsive subject area and in the process the artificial and inhibiting barriers between subjects such as geography and history have been broken down.

- Theme 3: A constructivist and humanitarian approach to teaching and learning - This is translated as developing students' understanding through directed learning by which the student is empowered to explore and discover, with teachers facilitating learning rather than being instructors. In such a humanistic system, the learner is important and we are all learners with different strengths and weaknesses.

\section{iii. 1995 - The Education Forum's Social Studies in the New Zealand} Curriculum: A Submission on the Draft

In the education reform process, a very strong and influential voice on behalf of neo-liberalism has been the New Zealand Business Roundtable. To support the establishment of their agenda in the education area, they have gathered together a group of influential people and established the Education Forum. The Education Forum responded to the Draft by hiring an Australian academic to analyse and provide a response to it. This response contained arguments largely in favour of retaining the status quo. It argued from ideological and pedagogical perspectives that the Draft was not only flawed but also unsalvageable:

It is the considered judgment of the Education Forum that the Draft Social Studies Curriculum statement (hereinafter "the Draft") has grave deficiencies. It trivialises serious and difficult educational issues; it is distorted by ideological preconceptions throughout; it is vague on the critical issue of assessment; it demeans our laws and government by undervaluing their European inheritance; it makes impossible any coherent or systematic understanding of subjects which are the basis of geography, history, and economics - indeed, on the evidence of the Draft, a student who had taken the Resources and Economic Activities strand throughout his or her school career would end up with only the shakiest idea of how a modern economy works, and perhaps no idea at all. (Education Forum, 1995, p. i)

The Education Forum argued that students need not only to be creative and exploratory but also to be provided with a strong foundation in all of the disciplines subsumed under the social studies banner (they mention geography, history and economics). They also argued that in order to understand these traditional disciplines in a meaningful and thorough way there is no substitute for putting in hard work (while they see these "softer" alternatives as being vague and lacking in substance). They were also critical of what could be described as a "politically correct" over-emphasis on things Maori (and the Draft's bicultural rather than multicultural emphasis) and the apparent lack of reference to New Zealand's rich British and European cultural heritage, both in terms of its various institutions, such as the legal and parliamentary system, and its rich intellectual tradition.

The Education Forum criticised the Draft as intellectually incoherent and for not presenting a body of substance and integrity upon which to build a curriculum. In its overview of the two areas selected for critique - place and environment; and time, continuity and change - the Forum was scathing. They referred to the sample topics as an "eccentric selection of historical events" (p. 11).

They were above all entirely dismissive of the Places and Environment strand:

Despite all the talk about "skills", this strand excludes even the basic verbal equipment needed for geographical understanding. Out go such terms and concepts as physical regions, map projections, scale, latitude and longitude, contours, determinants of weather and climate, atmosphere, winds and pressures, currents and tides, shoreline cycles, soil types, and mineral resources and their distribution. In their place come "people's perceptions of different environments and the reasons for these perceptions", something to be illustrated by such topics as "television images in the USA", "mining in Nauru", and "lifestyles of Maori in the fifteenth century". Out go landforms, glaciation, erosion, land use, and patterns of settlement. In come "implementing recommendations from the Earth Summit", "uranium mining in Australia", "resolving claims arising from the Treaty of Waitangi", and endless discussion about whether the world is getting hotter and how big the ozone hole is. It goes without saying that there is no systematic development of skills in 
drawing timelines and charts, or indeed any other devices for strengthening a sense of chronology and an understanding of both geological and social evolution. (pp. ii-iii)

They provided an alternative curriculum with alternative strands and what they described as five "great perennial themes concerning human thought, organisation, and interaction with the material environment". They also provided an appendix which outlines British curriculum materials missing from the Draft.

So what, then, are the themes which emerge from the Education Forum's response to the Draft? They can be summarised as follows:

- Theme 1: The retention of traditional disciplines -The traditional areas of history, geography and economics have distinct histories and theoretical foundations. If they are thrown out, then everything that has been built up will be lost. These need to be further strengthened and integrated into the education system to a greater degree rather than being abandoned.

- Theme 2: Teaching and learning are serious business - In the Draft, there is a sense that the approach to teaching is not taken seriously enough, that the emphasis is on soft approaches, through projects and exploration, and that this avoids the hard work of learning an important knowledge base.

- Theme 3: We must value, acknowledge and build on our traditional European historical and knowledge base - What is of most value in contemporary New Zealand comes from its European past. It is the source of New Zealand's legal and political system and its intellectual heritage. While we must acknowledge our current situation, let us not lose sight of our historical roots.

- Theme 4: Economics is a serious area of study - What was of concern to the Education Forum (and to key New Right advocates such as the Employers' Federation and Enterprise New Zealand) was a perceived ineffectiveness of the school system in meeting the needs of the economy. Economics should be treated as a subject in its own right, and given a prominent place within a new social studies curriculum. In the Draft, economics is treated as an unwanted appendage surrounded by less worthy "soft" subjects. As such, it is denied what should be its rightful status as the most important of the social sciences. iv. 1996 - Social Studies in the New Zealand Curriculum: Revised Draft

In response to the criticism by the Education Forum and others, the Ministry of Education re-examined the Draft and produced the Revised Draft, which appears to attempt to appease those who objected to the first draft, with particular reference to the criticisms that it had been vague and lacking in rigour. However, in the Revised Draft the strength of vision of the first draft is removed but not replaced either with the equally robust vision of the Education Forum or with anything else of standing. The new, carefully worded and toned-down statement about social studies illustrates this:

Two aims were identified for social studies: "knowledge and understanding of people and their interactions, and participation in a changing society as confident, informed and responsible citizens." (Ministry of Education, 1996, p. 11)

Although there is reference to Maori culture in various forms, it is minimal. Learning about New Zealand focuses much more on status quo interests with a strong European focus. Although "Maori culture, Maori social structures, and Maori perspectives on contemporary systems, policies, and events", "the Treaty of Waitangi, its interpretation over time, and its application to current systems, policies, and events", and a section on people's ways of life before 1769 are present (p. 15), they are swamped by an emphasis upon more European concerns (such as "the development of different industries, technologies, and occupations and their impact on New Zealand life in the past, present, and possible future; the organisation of employment, both paid and unpaid, and how producers, businesses, voluntary organisations, and services operate" (p. 15). The neo-liberal agenda was clearly gaining a foothold.

The Revised Draft also toned down the bicultural for a more multicultural perspective. Smythe is quoted in the Education Review (Matheson, 1997, p. 8) as describing this patronising and marginalising attitude to cultural politics as a plastic tiki. Marsick, a senior social studies teacher and resources developer from Howick College, noted in a similar vein that the Revised Draft "no longer encouraged students to challenge society and think in depth" (p. 8).

Although the Revised Draft was clearly an attempt to appease all interested parties while retaining some of the basic thinking and structures of the Draft, it didn't work! The response from all parties was not supportive, and this middle-of-the-road document was rejected by all. 
v. 1997-Social Studies in the New Zealand Curriculum - Final

In 1997, the final draft of the Social Studies in the New Zealand Curriculum was released. This was to become our social studies curriculum.

In the introduction to the final draft, the following definition of social studies is given:

Social studies is the systematic study of an integrated body of content drawn from the social sciences and the humanities. It enables students to develop their knowledge and understandings of the diverse and dynamic nature of society and of how interactions occur among cultures, societies, and environments. Students develop and apply skills as they investigate society, explore issues, make decisions, and work cooperatively with others. The understandings and skills they develop enable them to participate in society as informed, confident, and responsible citizens. (Ministry of Education, 1997, p. 7)

In the document, the original five learning strands from the original Draft have been reintroduced (social organisation; culture and heritage; place and environment; time, continuity and change; and resources and economic activities), but these areas are described in a more muted fashion than in the Draft, and with less emphasis on the Pacific region, biculturalism and New Zealand's Maori heritage and identity.

Central to the curriculum and interweaving with the five learning strands are what is referred to as three inter-related processes (inquiry, values exploration and social decision-making). The achievement aim of these processes is described as follows: "Students will develop skills as they use the social studies processes: to learn about society and to enable them to participate responsibly in society" (p. 19).

The earlier emphasis on critical faculties and essential skills is moved sideways and placed in a context of achievement objectives in relation to a relativistic, postmodern stance in which all things are valued equally. The radical, bicultural, Pacific-based Aotearoa of the Draft is replaced by a more multicultural, Western European as well as Maori New Zealand in the final version. In this context, the assertion that students "will be challenged to think clearly and critically about human behaviour, and to explore different values and viewpoints" (Ministry of Education, 1997, p. 14) is circumscribed and more limited than it was in the Draft.

\section{Unreal Tournament: Whose Values Win Out?}

Unreal Tournament is a game. Participating in society is not. The arguably prime dual functions of education are to inform students about the past and familiarise them with their cultural heritage, while at the same time giving them the skills to be critical about morality, values and society. An analysis of the versions that led up to the final social studies curriculum indicates that these dual functions have received different weightings and emphases during the drafting processes. Whereas a liberal and democratic education system is likely to be based on critical and reflective skills (as evidenced in the Draft in the seven specifically designed social studies skills - decision-making, critical thinking, creative thinking, values exploration, communication, research and enquiry, and social and cooperative skills), a neo-liberal education system is likely to be based on competitive and entrepreneurial skills (as introduced in the Revised Draft and evidenced in the Framework in the eight essential skills - communication, numeracy, information, problem- solving, self-management and competitive, social and cooperative, physical, and work and study skills).

So is there a winner in this struggle over the social studies curriculum as represented in the final social studies curriculum statement? The following is my synopsis.

In the final document, the Draft's Theme 1: A sense of revisionism which advocated a social studies curriculum firmly grounded in the contemporary Aotearoa New Zealand context is clearly central, although the wording is more restrained than in the Draft and social action is there more by implication than insistence. Issues relating to European history and multiculturalism (as opposed to biculturalism) are acknowledged and addressed, but are balanced by reference to Maori culture and New Zealand's position in the Pacific. In this respect, the Education Forum's Theme 3: We must value, acknowledge and build on our traditional European historical and knowledge base is the loser. The Draft is the winner.

Similarly, the Draft's Theme 2: Adopting an holistic and postmodern approach is clearly the winner over the Education Forum's Theme 1: The retention of traditional disciplines.

The Education Forum's Theme 4: Economics is a serious area of study, is handled by dealing more specifically with economic issues (which the Draft largely ignored) but having an overall ecological approach to the area, thus keeping it firmly under the social studies 
umbrella rather than as a stand-alone area developing separate themes - another victory largely for the Draft.

As for the debate between the Education Forum's Theme 2: Teaching and learning are serious business versus the Draft's Theme 3: A constructivist and humanitarian approach to teaching and learning, again it is the Draft which won out. For all intents and purposes, the final draft uses a constructivist approach. I would argue that the case made by the Education Forum against the constructivist approach is an old argument based on different interpretations of what knowledge is, what should be selected and taught, and how this should be done. In essence, these two arguments are based on two different world views and visions for education. It was the Draft's vision that was supported in this instance.

At the beginning of this article, I discussed the simulated combat game Unreal Tournament. The purpose of that exercise was to use a randomly selected example to illustrate how for a not overly-complex but interesting and relevant scenario, I was able to go through an analytical, critical and reflective process. As a result, I was able to:

i. lay out the issues as they were stated by the participants,

ii. tease out what was not stated but could be implied, and

iii. come up with a range of responses to the scenario.

I argued that this was the stuff of social studies and, in effect, that it met the criteria for a social studies curriculum, as described by Barr (1997). He argues that, on the one hand, social studies has a conservative intent in that it is meant to teach and reinforce society's foundational values, societal truths and democratic principles, and on the other that it has a radical intent in that its purpose is to develop critical and reflective thinking that can challenge the status quo, break the rules and provide possible radical alternatives. It is about maintaining, thinking, challenging and - when and where appropriate - changing.

I would argue that despite good intentions the final statement is flawed. Ideologically and in terms of the values that are suggested, there is a sense that despite the apparent victories of the Draft perspective, pragmatism has sometimes replaced principles, ${ }^{2}$ principles have been tempered by compromise, and encouragement of thinking and critical analysis has been subsumed by the need to meet the needs of assessment. Thus, while the new approach of the Draft is recognisably present, it sits in a context that bows to neo-liberalism and pays lip-service to constructivism. Is this the nature of things to come under a Third Way, of making ideologically unsound compromises by marrying "the best" of two oppositional ideological stances? As my teenage daughter would say, "I don't think so!"

\section{Notes}

1. I would like to thank Fiona Beals for her conference paper on the social studies curriculum (See references) and for alerting me to the work of Barr, Parker \& Jarolimek, and Engle \& Ochoa.

2. Sullivan and Clark (2002) develop this critique further by showing how the values embedded in the final curriculum statement contradict its implied social democratic ideological intentions.

\section{References}

Barr, H. (1997). Defining social studies. Teachers and curriculum, 1, 6-12.

Beals, F. (2001, December). Reconstructing identity: An exploration into the limitations of identity construction in the current social studies curriculum. Murdoch Symposium on Race and Prejudice, Fremantle, Australia.

Department of Education. (1988a). Administering for excellence: Effective administration in education (Picot Report). Wellington: Government Printer.

Department of Education. (1988b). Tomorrow's schools: The reform of educational administration in New Zealand. Wellington: Government Printer.

Education Forum. (1995). Social studies in the curriculum: A submission on the draft. Wellington: Education Forum.

Engle, S. \& Ochoa, A. (1988). Education for democratic citizenship: Decision making in the social studies curriculum. New York: Teachers' College Press.

Lauder, H. (1990). The New Right revolution and education in New Zealand. In S. Middleton, J. Codd \& A. Jones (Eds.), New Zealand educational policy today: Critical perspectives. Wellington: Allen and Unwin.

Matheson, D. (1997, April 9). If their aim were true. New Zealand Education Review, pp. 7-8.

Ministry of Education. (1990). Today's schools: A review of the education reform implementation process (Lough Report). Wellington: Ministry of Education. 
Ministry of Education. (1993). The New Zealand curriculum framework. Wellington: Learning Media

Ministry of Education. (1994). Social studies in the New Zealand curriculum: Draft. Wellington: Learning Media.

Ministry of Education. (1996). Social Studies in the New Zealand curriculum: Revised draft, Wellington: Learning Media.

Ministry of Education. (1997). Social studies in the New Zealand curriculum. Wellington: Learning Media.

Parker, W., \& Jarolimek, J. (1984). Citizenship and the critical role of the social studies. Boulder, Colorado: ERIC Clearing House for Social Studies/Social Science Education.

Smith, L. (1991). Education policy: Investing in people our greatest asset. Wellington: Ministry of Education.

Sullivan, K. (1997). They've opened Pandora's Box: Educational reform, the New Right and teachers' ideologies. In M. Olssen \& $\mathrm{K}$. Morris-Matthews (Eds.), Education policy in New Zealand: The 1990s and Beyond (pp 251-282). Palmerston North: Dunmore Press.

Sullivan, K. (1999). Teacher standards and professionalism: Contested perspectives in a decade of reform. New Zealand Journal of Educational Studies Special Issue: A Decade of Reform in New Zealand Education: Where to Now?, 34(1),144-155.

Sullivan, K., \& Clark, J. (2002, forthcoming). The transmission of ideology and values through education: An examination of the New Zealand social studies curriculum. In A. O'Neill, J. Clark \& R. Openshaw (Eds.), The New Zealand curriculum framework: Knowledge, politics and markets. Palmerston North: Dunmore Press.

The Treasury. (1987). Government management: Brief to the incoming government 1987. Volume II: Education issues, Wellington: Government Printer.

\section{The author}

Keith Sullivan is a Senior Lecturer in the School of Education at Victoria

University of Wellington.

His Email address is: Keith.Sullivan@vuw.ac.nz. 